\section{Jahre DGfK-Sektion} Südbaden

Am 24. November 2016 feierte die nach den Worten von Herrn Prof. Dr.-Ing. Manfred Weisensee „kleine aber feine“ DGfK-Sektion Südbaden feierlich ihr 60-jähriges Bestehen mit einem Festkolloquium im Historischen Kaufhaus am Münsterplatz in Freiburg im Breisgau.

Nach Gründung am 17. November 1956 wurde wieder ein Termin im November gewählt. Knapp 40 Teilnehmer trafen sich, um in schönem Ambiente den interessanten Fachvorträgen zu folgen und sich in den Pausen intensiv über kartographische Themen auszutauschen. Schirmherr der Veranstaltung war der Erste Bürgermeister der Stadt Freiburg im Breisgau Herr Otto Neideck.

Die Veranstaltung war geprägt von vielfältigen Themen und Teilnehmern aus der Region Freiburg und der Schweiz. Einführende Worte fanden der Präsident der DGfK Prof. Dr.-Ing. Manfred Weisensee, der Präsident der SGK Dr. Thomas Schulz und die Vorsitzende der Sektion Südbaden Dipl.-Ing. (FH) Bettina Schmücking.

Der erste Themenblock hatte direkte Verbindung zur Örtlichkeit Freiburg: Erst referierte Dr.

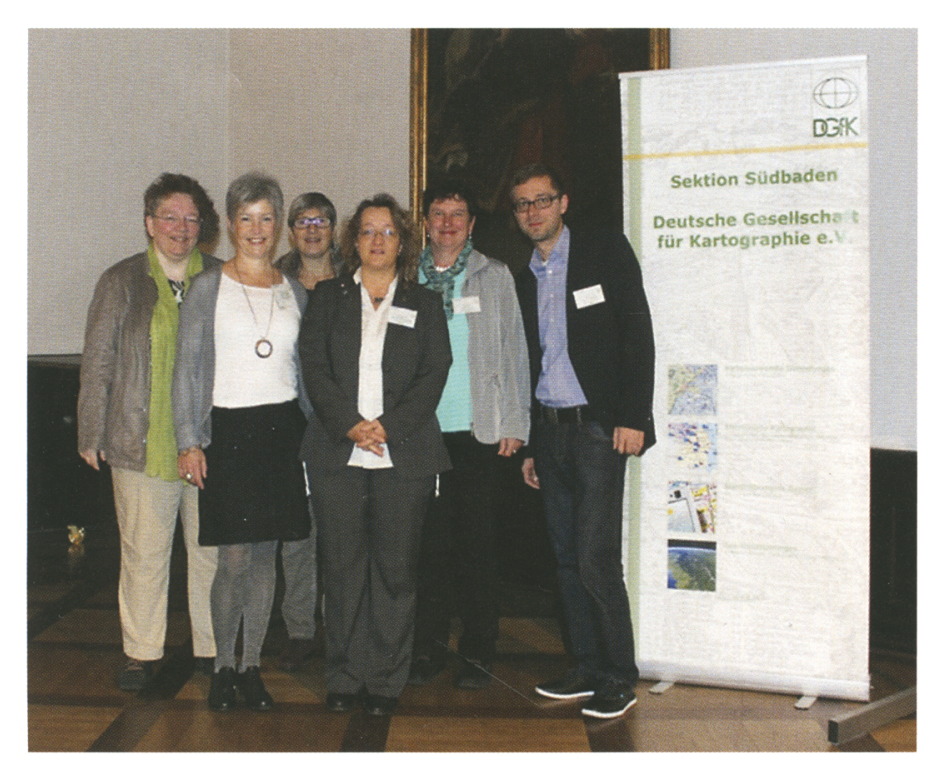

Abb. 1: Das Organisationsteam (Foto: Peter Schaufuß)

Philipp Golecki in einem sehr interessanten und praxisnahen Vortrag über GIS-Anwendungen beim Amt für Brand- und Katastrophenschutz Freiburg, gefolgt von Dipl.-Ing. Kathrin Schonefeld über das 3D-Stadtmodell der Stadt Freiburg. Im weiteren Verlauf wurden zwei Mitglieder für 60 Jahre Zugehörigkeit zur Sektion geehrt: Herr Dr. Kötter (zugleich auch Gründungsmitglied) und Herr Dipl.-Ing. Seeger.

Der Nachmittag startete ebenfalls spannend mit einem Vortrag von Frau Dipl.-Ing. (FH) Ursula Buck (Universität Bern) über den Einsatz von Vermessungstechnik in der Forensik - präsentiert an Beispielen aus ihrem spannenden Arbeitsalltag. Der nächste Vortrag von Dipl.-Hyd. Alexander Krämer (Firma WWL, Bad Krozingen) beschäftigte sich mit dem Einsatz von Vermessungsdrohnen zur Erfassung von Geodaten für die Umweltplanung. Danach präsentierte Prof. Hans-Jörg Stark vom Grundbuch- und Vermessungsamt Basel-Stadt den kantonalen Geodatenviewer der Stadt Basel und diskutierte, ob es ein Wiederspruch ist, historische Karten in digitaler Form darzustellen.

Zum Abschluss referierte Prof. Dr.-Ing. Manfred Weisensee über „Kartographie der Zukunft - Zukunft der Kartographie“, um das Thema Kartographie gebührend

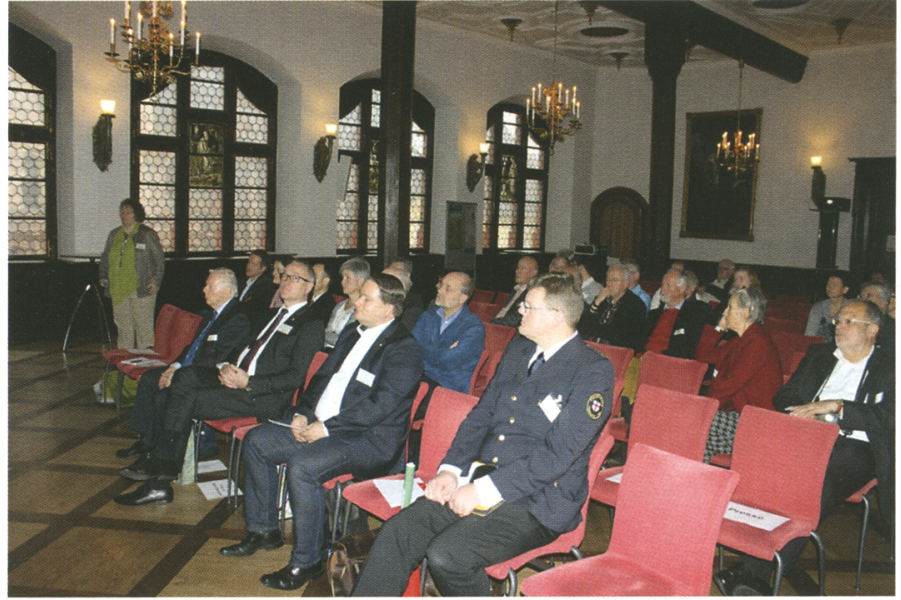

Abb. 2: Interessiertes Publikum bei den Grußworten und Fachvorträgen (Foto: Peter Schaufuß)

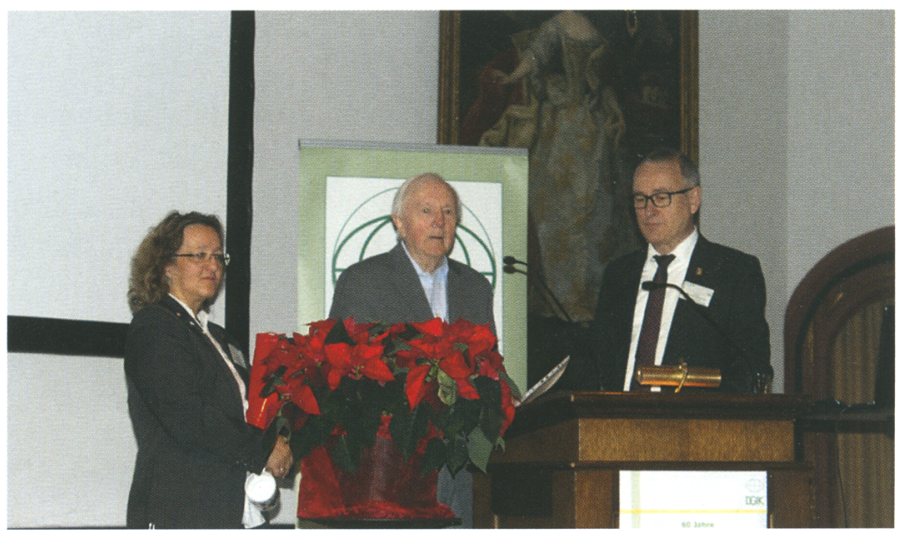

Abb. 3: Ehrung von Herrn Kötter für 60 Jahre Mitgliedschaft in der DGfK (Foto: Peter Schaufuß)

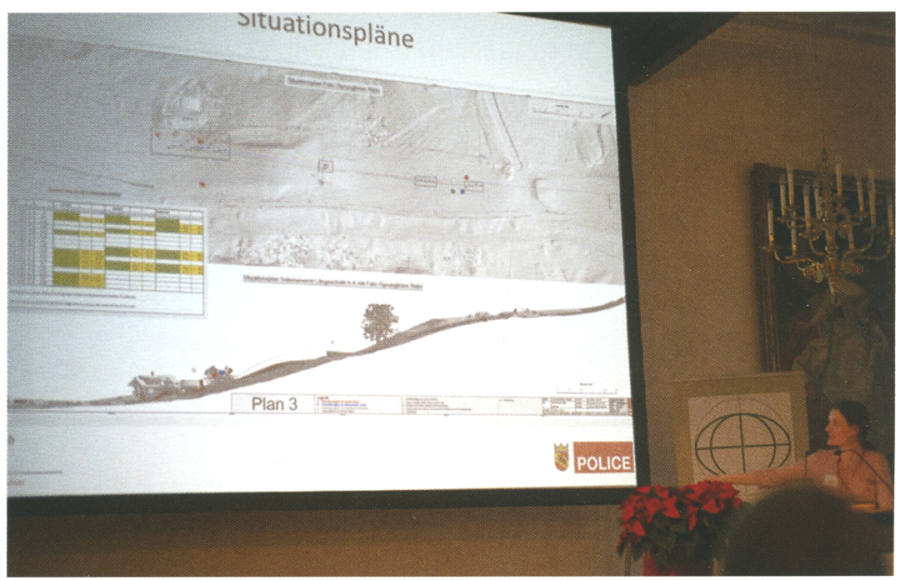

Abb. 4: Frau U. Buck bei inrem Vortrag (Foto: Peter Schaufuß)

abzurunden und einen Blick in die Glaskugel zu wagen. Abschließend wies der Präsident der DGfK darauf hin, dass diese Veranstaltung eine der letzten im Rahmen des von der ICC ausgerufenen "Internationalen Jahres der Karte 2015/2016“ sei und hoffte auf eine weitere Präsenz und Stärkung der Kartographie und Geomatik in der Zukunft.
In einem Nachkolloquium in einer nahegelegenen Gaststätte konnten noch viele der präsentierten Themen, aber auch Weiteres abschließend diskutiert werden.

Dipl. Ing. (FH) Peter Schaufuß, stellvertretender Vorsitzender der DGfK Sektion Südbaden 